\title{
Pre- and post-parturial aspects of scorpion reproduction: a review
}

\author{
MichaEL R. WARBURG \\ Dept. of Biology, Technion-Israel Institute of Technology, Haifa 32000, Israel; e-mail: warburg@tx.technion.ac.il
}

Key words. Scorpiones, fertilization, insemination, gestation, parturition, birth

\begin{abstract}
Although scorpions are an ancient group their method of reproduction is rather complex and poorly studied. This review aims at clarifying some of the aspects of their reproduction that are important for understanding the reproductive ecology of other arthropods, including insects. The following aspects of scorpion reproduction are discussed and reviewed: mating, insemination, fertilization, gestation, parturition and birth. The onset of gestation and its duration are difficult to determine as both depend on the time of fertilization, for which there are no accurate estimates. There are only a few records of the time between birth and emergence of a larva from the maternal envelope in apoikogenic scorpions, which is important for a better understanding of ovoviviparity. All these questions are important as the answers will greatly enhance our understanding of the population ecology of scorpions in terms of the recruitment rates of cohorts and their chances of survival.
\end{abstract}

\section{INTRODUCTION}

In spite of their obvious medical importance we know less about scorpions than other arachnids. Scorpions do not lay eggs and unlike other arachnids their embryos complete their development in the ovariuterus inside follicles or diverticulae (Benton, 2001; Brown, 2001; Warburg, 2001, 2010). The last review of some of the aspects of scorpion reproduction discussed here appeared 20 years ago (Polis \& Sissom, 1990) and some have never been previously discussed. This review does not discuss other important aspects of female scorpion reproduction such as oogenesis and embryogenesis (Warburg, 2010, 2012) or events significant to scorpion reproduction starting at parturition and continuing into juvenile and adult life (see Warburg, 2011). It reviews and discusses mating, insemination, gestation, modes of reproduction, parturition, breeding season and birth in scorpions. The present review aims to clarify some of these subjects, which are of interest not only to arthropod research, but also to developmental and ecological biology.

\section{MATING AND INSEMINATION}

Breeding starts with mating, which is observed throughout the breeding season. There are several observations of mating in nature, both on the behavioral aspects and its duration. The breeding period lasts until parturition takes place. In Paruroctonus (now Smeringurus) mesaensis Stahnke, 1957 it lasts for 5-6 months (between May-October) (Table X in Polis \& Farley, 1979; Table 4.2 in Polis \& Sissom, 1990).

\section{Single or multiple mating}

Generally scorpions mate once annually and females are incapable of being inseminated more than once in the same breeding season because of a genital plug formed after mating, which blocks the entrance until just before parturition (Peretti, 2010). Varela (1961) records Bothriurus bonariensis (Koch, 1842) females rejecting males attempting to mate after parturition. However, more than one mating of the same female has been observed. Thus, Matthiessen (1968) records a female of Rhopalus rochai Borelli, 1910, accepting a male $24 \mathrm{~h}$ after parturition. Several post-partum females of $S$. mesaensis are recorded mating but not gravid females (Polis \& Farley, 1979). Gravid females are those in the last period of gestation when their condition is obvious from their size. Armas (1987) records multiple mating in the diplocentrids, Didymocentrus trinitarius (Franganillo, 1930), Cazierius gundlachii (Karsch, 1880) and buthid, Rhopalus junceus (Scopoli, 1763). A. Peretti (1997, and pers. comm.) records males of Rhopalus garridoi mating more than once with different females. Likewise, B. bonariensis females repeatedly mate (up to five times during a season). In Centruroides bicolor (Pocock, 1898), the same pair can mate three times in four weeks. Polis \& Mohnac (1990) report a female Vaejovis eusthenura (Wood, 1863) mating while still carrying offspring on her back.

The low number of times a female is observed mating (i.e. taking up a spermatophore) could imply that sperm are stored. Consequently, the stored sperm could originate either from a single male or from a number of different males.

\section{Single and multiple inseminations}

Some species of scorpions are capable of producing more than one brood from a single insemination, e.g. Lychas tricarinatus (Simon, 1884) females can produce three broods from a single insemination. Sperm storage is ruled out as no sperm was found in the ovariuterus (Mathew, 1962, p. 347). Parthenogenesis is also unlikely as the sex ratio in this species is about $1: 1$.

In Isometrus maculatus (De Geer, 1778) females can give birth five times following a single insemination (Probst, 1968, 1972). Kovoor et al. (1987) review the cases where 4-5 broods were recorded following a single 
insemination. These are for three genera: Tityus, Isometrus and Centruroides. They checked if sperm is retained in the spermathecae but microscopical examination failed to reveal the presence of sperm. This may indicate that embryonic diapause occurs in these species (see Warburg 2010, 2012). Liocheles australasiae (F., 1775) reared in the laboratory can produce five successive generations in seven years (Makioka, 1992; Yamazaki \& Makioka, 2005).

Centuroides bicolor females that receive sperm from three spermatophores from the same male gave birth to offspring over a period of six days (A. Peretti, pers. comm.). The males appear to be able to produce a pair of spermatophores every 3 to 7 days. Thus in the buthid Zabius fuscus (Thorell, 1876), hemispermatophore regeneration takes between 10 to 14 days. Recently Ross (2009), studying Tityus (Atreus) magnimanus Pocock, 1897 , found that this species is capable of mating on three consecutive times.

Only in the laboratory is it possible to determine whether a female scorpion mates only once. If this is the case then sperm stored in a single spermatophore is used more than once, which could result in multiple fertilizations of ova from a single insemination.

\section{GESTATION PERIOD}

\section{Gestation period}

Gestation starts with fertilization and ends with parturition or birth of the larvae. How can the time (date) or duration of gestation be determined? Presumably this can only be done by observing gravid females at an advanced stage of gestation. It is not possible to identify the early stages of gestation unless the female is dissected. Therefore, it is not possible to determine the number of days a female is gravid (i.e. the gestation period) since it is unknown when her eggs are fertilized. This means that the gestation periods as cited in the literature are based on when a female was observed mating i.e. taking up a spermatophore (or being inseminated). However, this may not be the onset of gestation since the time of fertilization remains unknown.

Subburam \& Reddy (1978, Table 1) determined the developmental stage of gravid females of Pandinus imperator C.L. Koch, 1841 and Heterometrus fulvipes (C.L. Koch, 1837). They record that during May-June most females (90-100\%) carried last stage embryos (Stage VIII). In scorpions, the gestation period lasts between 1.5-18 months (for data available in 1977 for 19 species see Table X in Polis \& Farley, 1979, Table 4.2 in Polis \& Sissom, 1990 summarizes the data up to 1985 and recently Table 1 in Outeda-Jorge et al., 2009 summarizes the data for South American species). The gestation period in the laboratory of female Leiurus quinquestriatus (Ehrenberg, 1828) that were isolated immediately after mating is on average 185 days (ranging between 155-227 days) (Ross, 2009). Parturition in Tityus bahiensis (Perty, 1833 ) in the laboratory occurs 125 days after mating (Matthiesen, 1970).
However, being inseminated does not necessarily mean that the ova are fertilized at the same time as the female is inseminated. There is evidence to the contrary (R. Stockmann, pers. comm.): in Euscorpius tergestinus (carpathicus) (C.L. Koch, 1837) there are no oocytes in the lumen of the ovariuterus (i.e. ovulation has not occurred) $30 \mathrm{~h}$ after the uptake of the spermatophore. During this period individual spermatozoa are present in both the lumen and wall of the ovariuterus. This indicates that the duration of the gestation period can only be determined if the scorpions are mated in the laboratory.

\section{Duration of gestation}

The literature on this subject is summarized for 20 and 28 species in Table X in Polis \& Farley (1979) and Table 4.2 in Polis \& Sissom (1990) respectively. This data indicates that gestation lasts on average 9.6 months in bothriurids, five in buthids, 12 in both vaejovids and scorpionids, 16.8 in ischniurids and 13.5 in diplocentrids (see Table 4.5 in Polis \& Sissom, 1990). Peretti (1997) gives considerably shorter durations of gestation in two buthids and four bothriurids, ranging between 1.5-18 months. The shortest gestation period (1.5 months) is that recorded for Orthochirus innesii (E. Simon) (Shulov \& Amitai, 1960) and the longest (18 months) for Opisthacanthus asper (Peters, 1861), Opisthacanthus cayaporum Vellard, 1932, and Urodacus yaschenkoi (Birula, 1903) (Shorthouse \& Marples, 1982).

Peretti (1997) gives data for some Argentinian scorpions. Mahsberg (2001, Table 10.2) records both the time of insemination and birth for $P$. imperator and $H$. fulvipes for which the average gestation period is 370 days (range 298-455 days) and 436 days (range 413-465 days), respectively.

However, how can the duration of gestation be determined if the time of fertilization is unknown? In other words, the data in the literature are most likely conservative since they could not possibly take into account the early stages of oogenesis, which can only be identified microscopically.

\section{Frequency (number of gestations)}

Several periods of gestation are recorded for Euscorpius italicus (Herbst, 1800) (Angermann, 1957) and Tityus serrulatus Lutz \& Mello, 1922, which give birth 3-4 times (Matthiesen, 1962). The number of embryos in $U$. yaschenkoi indicates there are possibly three pregnancies (Shorthouse \& Marples, 1982) and a few Centuroides spp give birth yearly (Armas \& Hernandez Contreras, 1981).

\section{Intervals between parturitions}

Probst (1968) records in that the time between two consecutive parturitions in I. maculatus is a constant $72-80$ days, which is the same as gestation period (time required for embryonic development). In Centruroides spp there is one to several gestations per year, which occur at 2-4 months intervals. The same is recorded for S. mesaensis, one female of which was gravid in three consecutive years (Polis \& Farley, 1979). Gestations at 2-4 months 
intervals are recorded in tropical regions (Williams, 1987).

\section{MODES OF REPRODUCTION}

Three terms are used to describe the modes of reproduction recorded in vertebrates: oviparity, viviparity and ovoviviparity.

\section{Oviparity}

Oviparity is defined as the release of eggs as soon as they are fully formed; each egg usually consists of a single cell, the fertilized ovum. Eggs may need a period of incubation to complete their development outside the female's body. So far this form of reproduction is not recorded in scorpions.

\section{Ovoviviparity}

Two different modes of viviparity are recorded in scorpions: live-bearing in katoikogenic scorpions and ovoviviparity in apoikogenic scorpions, in which the larvae remain wrapped-up in maternal membranes inside a female's body until hatching occurs and a fully-formed offspring is born. Warburg (2010) has reviewed the female reproductive system. Larvae of $O$. innesii and $L$. quinquestriatus (see Shulov et al., 1960) are born wrapped in two embryonic membranes, which they shed immediately at birth. The time it takes for a newborn apoikogenic scorpion larva to rid itself of birth membranes for scorpions belonging to five families is given in Table 1 and ranges from a few seconds to two hours. Katoikogenous scorpions are generally born free of maternal membranes, but are clearly wrapped-up in membranes when inside the ovariuterus (Fig. 1B).

Does this mode of reproduction qualify as ovoviviparous? Since apoikogenic scorpions are not enclosed in an egg-shell but in a double membrane they may not be ovoviviparous. In the literature they are considered to be viviparous since they do not lay eggs. According to Francke (1982, p. 30) "ovoviviparity is considered to be a condition where 14 mature ova develop within the reproductive system of the female, but in which no fertilization nutrients are obtained from the mother by the developing embryo". He concludes that "therefore all scorpions must be considered to be viviparous". However, the embryos of apoikogenic scorpions also obtain nutrients from their mother (Mathew, 1960; Farley, 1996, 1999). This indi-

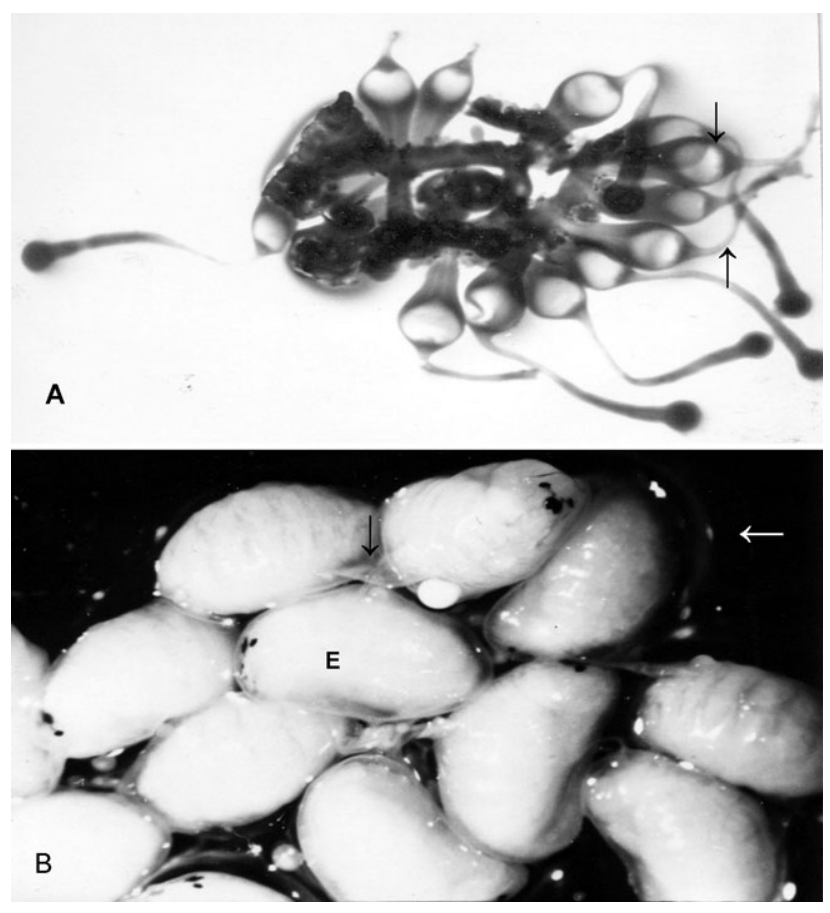

Fig. 1. N. hierichonticus (light microscope). A - ovariuterus with embryonic diverticulae containing embryos (arrows); B embryos (E) wrapped in membranes (arrows) inside an ovariuterus.

cates there are several modes of reproduction in which in addition to the yolk in the eggs the embryos obtain further nutrients from their mother. In insects ovoviviparity does not imply the further provisioning by the mother of the developing eggs, but only the existence of a chamber in which the brood develops. My view is that most apoikogenous scorpions are ovoviviparous but seem to evolve into becoming viviparous.

\section{Viviparity}

Recently, H. Greven (pers. comm.) suggested replacing this term by criteria based on embryo nutrition: a lecithotrophy-matrotrophy continuum in which embryonic development in lecithotrophic viviparous scorpions is exclusively dependent on yolk and in matrotrophic viviparous scorpions on maternal nutrition. There is there is a gradual increase in the supply of nutrition by the mother, first ions then water and small molecules and

TABLE 1. The duration of time between "egg laying" and emergence of larvae from maternal membranes in apoikogenic scorpions.

\begin{tabular}{lccc}
\hline Family & Species & Time (min) & Reference \\
\hline Bothriuridae & Bothriurus bonariensis (Koch, 1842) & "soon after" & Varela, 1961 \\
Buthidae & Leiurus quinquestriatus (Ehrenberg, 1828) & 5 & Abushama, 1968 \\
& Isometrus maculatus (De Geer, 1778) & "soon after" & Probst, 1972 \\
& Orthochirus innesi (E. Simon, 1910) & $\sim 1$ & Shulov et al., 1960 \\
Chactidae & Megacormus gertschi Diaz Najera, 1966 & "soon after" & Francke, 1979 \\
Hemiscorpiidae & Hemiscorpius leptutus Peters & $10-20$ & Dehghani et al., 2007 \\
Vaejovidae & Vaejovis spinigerus (Wood, 1863) & $5-15$ & Williams, 1969 \\
& Syntropis macrura Kraepelin & $30-120$ & Hjelle, 1974 \\
& Paruroctonus boreus (Girard, 1854) & $10-20$ & Tourtlotte, 1974 \\
\hline
\end{tabular}


later large molecules, in a lecithotrophy-matrotrophy continuum. He suggests that both apoikogenic and katoikogenic scorpions are viviparous.

\section{PARTURITION}

\section{Breeding season}

In most species of scorpion (outside the tropics) there is a single discrete, annual breeding season (Matthiesen, 1970; Makioka \& Koike, 1985; Makioka, 1992). Scorpions inhabiting tropical regions do not breed at a particular time of the year and produce several broods annually.

However, what is meant by breeding season or period needs clarification. Does it start with mating or is it synonymous with the gestation period or does it only include the parturition period, i.e. starts with the birth of the first and ends with the birth of the last larva? Perhaps the breeding season can be defined as the period between when males first seek out females for mating and when females no longer carry offspring on their backs. There is little information on the time of mating and the gestation period in nature. The breeding period referred to in the literature is essentially that over which gravid females in the later stages of gestation or during the post-partum stage when carrying young on their backs are recorded.

Polis \& Farley (1979, see Table X), summarize data up to 1977 on the birth dates of 33 species.

There are three main parameters directly related to parturition.

The period (i.e. dates) when it occurs. This is the breeding season when scorpions give birth to young.

The duration of the breeding period (i.e. parturition). The length of the period over which females in a given population give birth to young. In other words: the interval of time between the first and last female in a population giving birth to young during a given breeding season.

The number of parturitions per female. This is a measure of whether a female is capable of giving birth more than once in her lifetime (iteroparous) and if so, can it give birth on consecutive years.

Of these three events the first two are relatively well studied: breeding (delivery) period and the duration of the breeding (parturition) period.

\section{The number of parturitions per female}

A different way to estimate the number of times a female gives birth to offspring, is by counting the number of post-partum, degenerated diverticulae (for a more detailed account see Warburg, 2010, Figs 2-4).

Is a female capable of giving birth more than once in her lifetime? Yamazaki \& Makioka (2001) record that $L$. australasiae females can give birth to several broods the number of which is indicated by the number of empty (i.e. post-partum) diverticulae, which is roughly equal to the number of neonates.

\section{Can a female breed in consecutive years?}

Shorthouse (1971) dissected 35 females of $U$. yaschenkoi and counted the number of post-partum diver-

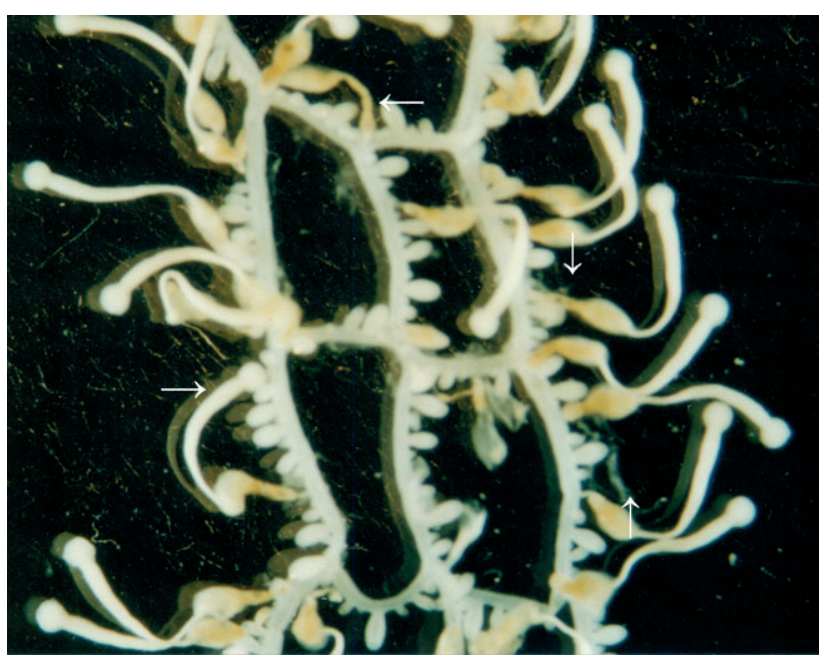

Fig. 2. N. hierichonticus ovariuterus six months after parturition. PPDs - arrows.

ticulae (PPDs), which are the embryonic diverticulae that previously housed the embryos that have moved into the ovariuterus (see Figs 1A, B, 2-4). There were no PPDs in half of the females $(51.4 \%)$, which indicates they had not bred during the previous breeding season. This would mean that $48.6 \%$ of female $U$. yaschenkoi bred the previous year. The average number of PPDs was 13.8 (ranging between 8-31). In two females there was more than double the average number of PPDs, which indicates they had bred twice previously.

\section{Percentage of gravid females in a population}

What is the percentage of breeding females in a population?

There are a few estimates of the percentages of females that are gravid in the field: $41.4 \%$ to $68 \%$ of females of $S$. mesaensis, Vaejovidae (Polis \& Farley, 1979) and 46\% of 516 females of $T$. serrulatus, Buthidae (Matthiesen, 1970). In other words, a female will breed either every other year or every third year.

The percentage of females of the apoikogenic scorpion Hottentotta judaicus (E. Simon, 1872) with PPDs is 13\%, of O. innesii 5.9\%, of C. w. judaicus (Birula, 1905) $10.5 \%$ and L. quinquestriatus $20.8 \%$. This might indicate the percentage of females that had bred previously.

Of the katoikogenic species $30 \%$ of the females of Scorpio maurus fuscus Ehrenberg, 1829 and 29.4\% of those of $N$. hierichonticus (E. Simon, 1872) had PPDs, which might also indicate the percentage that bred in the previous season. These figures may also indicate that only up to $6 \%$ (in O. innesii) and a maximum of $30 \%$ (in $S$. $\mathrm{m}$. fuscus) of the females breed annually. Thus, if only $6 \%$ of the oocytes in $O$. innesi post-partum are PPDs, then it is likely this is the size of the last litter produced in the previous breeding season. Likewise, in $S$. m. fuscus, the size of the last litter is indicated by the $30 \%$ of the diverticulae that are PPDs.

It is likely that these figures can be used to determine not only litter size but also the number of times a female has reproduced. For example, adult females of $O$. innesii 


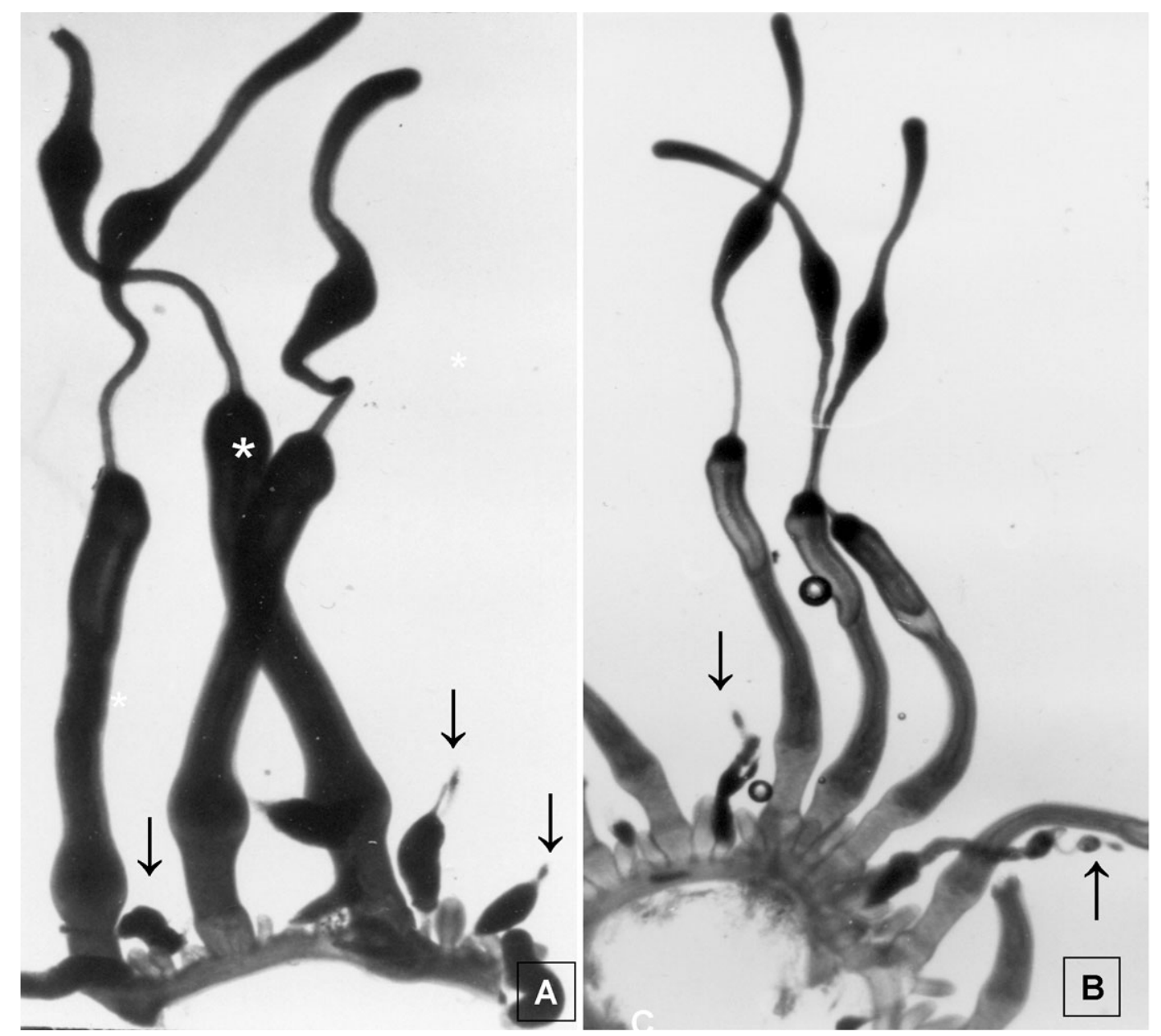

Fig. 3. S. maurus fuscus LM. A $-\times 12 ; \mathrm{B} \times 9$, arrows indicate post-partum diverticulae (PPDs) and asterisk - embryonic diverticulae (ED).

may breed only every 6th year and if short-lived may breed only once in their lifetime and $S . m$. fuscus females may breed only every 3 rd year.

The percentage of degenerating oocytes, diverticulae and scars that remain in the ovariuterus tubes (see Warburg, 2010) are recorded for some apoikogenic and katoikogenic species (summarized in Warburg, 2001). The number of degenerating oocytes can also be an indication of the size of the previous litter. Based on examining the ovariuterus of post-parturial females 3 to 9 months after parturition, the PPDs clearly shrink in size and change colour (Fig. 5, and Fig. 1c in Warburg, 2010).

\section{Duration of parturition}

The aspects of parturition that will be discussed in this section are the duration of the parturition period (i.e. the period during which females give birth) and duration of birth (i.e. the time it takes to produce a brood).

The duration of parturition in 25 species belonging to seven families is reviewed by Francke (1982, Table 1) and in 19 species belonging to seven families by Polis \& Sissom (1990, Table 4.2 therein). According to Williams (1969) the shortest parturition recorded is for Hadrurus arizonensis (Ewing, 1928), 10 young in $1 \mathrm{~h}$, and longest for Vaejovis spinigerus (Wood, 1863), 69 young in $7.5 \mathrm{~h}$.
In $H$. fulvipes the breeding season lasts two months (Subburam \& Reddy, 1981) and in Nebo the duration of the parturition period (i.e. the period during which scorpions are observed giving birth in the laboratory) lasts five months.

\section{BIRTH OF A BROOD}

\section{Date of birth}

Data on dates of birth are cited in Francke (1982, Table 1 there), for 66 species in Polis \& Sissom (1990, Table 4.2) and for 21 South American species of scorpion reviewed by Outeda-Jorge et al. (2009) (see also Table 1 therein).

\section{Duration of a cohort's birth}

The process of birth was described by several authors many years ago. These descriptions mainly focus on the behaviour of a female while giving birth, the frequency with which offspring are born and the way they climb onto their mother's back.

The time it takes from the beginning of emergence of the first until the birth of the last larva (i.e. duration of birth) has usually been recorded in the laboratory. In Diplocentrus spitzeri Stahnke, 1970, Francke (1981) it takes from 6 to $168 \mathrm{~min}(2.8 \mathrm{~h})$. One female gave birth to 

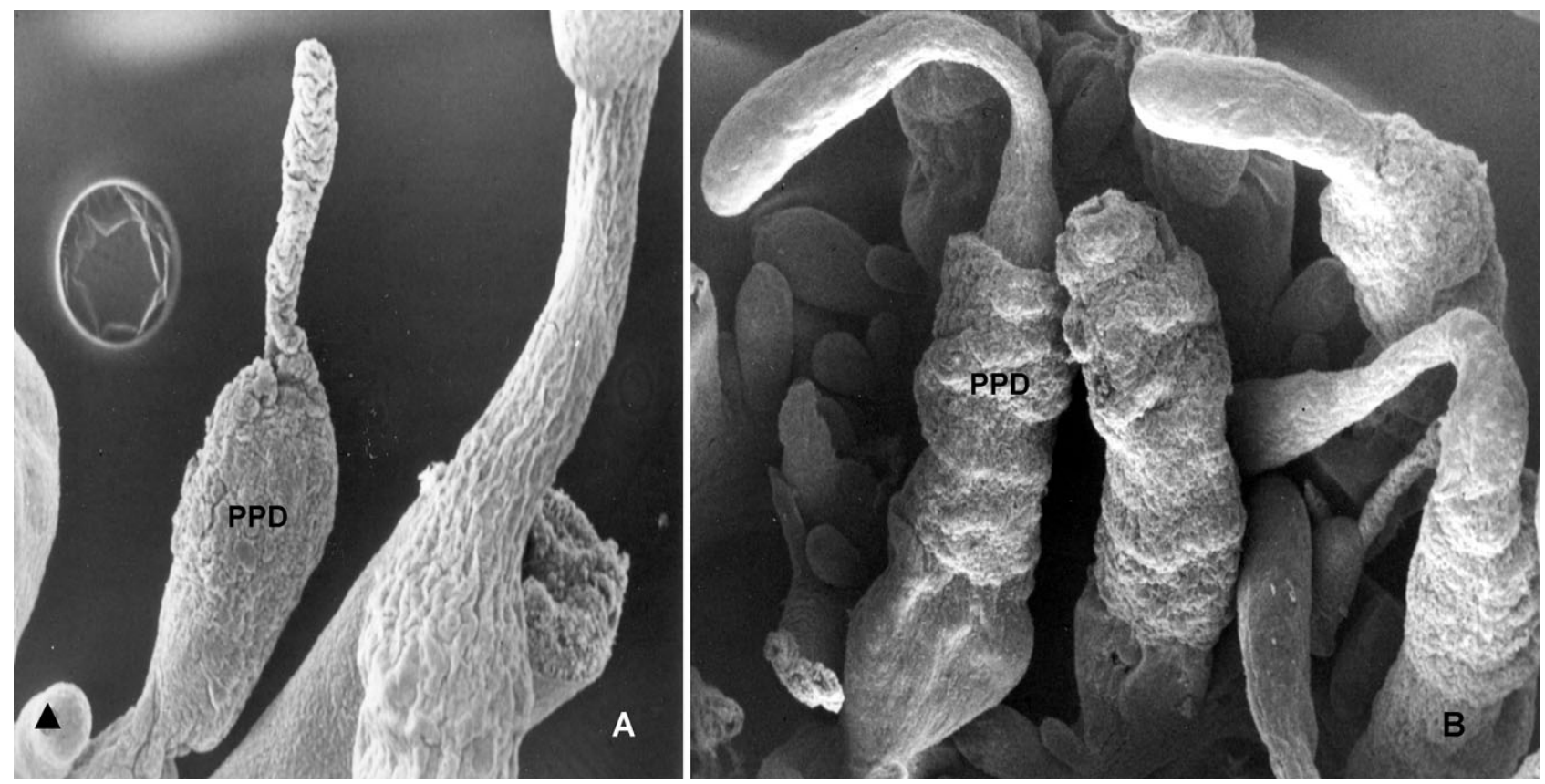

Fig. 4. S. maurus fuscus, Scanning Electron Microscope (SEM) pictures at a magnification of A $(\times 100)$ and B $(\times 150)$ showing PPD - post-partum and $\boldsymbol{\Delta}$ - rudimentary diverticuluae.

nine young over a period of $56 \mathrm{~h}$. The shortest parturition (i.e. birth) period recorded is $55 \mathrm{~min}$ for Centruroides guanensis cubanis (Armas, 1980) and the longest 10 days for Hadogenes sp. (Williams, 1969). In Syntropis macrura (Kraepelin, 1900) the birth of a litter takes $37 \mathrm{~h}$ (Hjelle, 1974). Generally, birth of a litter takes less than $24 \mathrm{~h}$ in apoikogenic scorpions (Francke, 1982). In $P$. imperator it generally lasts between 3 to $12 \mathrm{~h}$ (Ross, 2007). In Hemiscorpius lepturus Peters, 1861, the duration of the birth period ranges between 4 to $6 \mathrm{~h}$ (Dehghani et al., 2007).

\section{Duration of an individual's birth}

There are only a few records of the time it takes for an individual to be born and rid itself of its birth membranes in ovoviviparous apoikogenic scorpions, some of which are summarized in Table 1 . This is a very critical period since the newborn larva is immobile and quite helpless, still wrapped inside its birth membranes as shown in a

Different PPDs in $\mathbf{N}$. hierichonticus four months after parturition

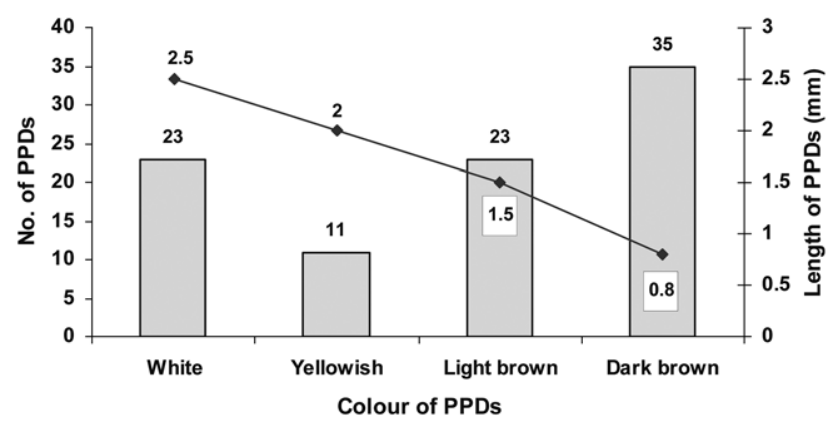

Fig. 5. Number (columns), length (line) and colour of PPDs associated with different broods of offspring. photograph of three newborn Vaejovis vorhiesi Stahnke, 1940 published by Williams (1969, Fig. 3 therein). The shorter this period is the sooner a larva can climb onto its mother's back and the greater its chances of surviving. The larvae of katoikogenic, viviparous scorpions do not face the same risk as those of $N$. hierichonticus Rosin \& Shulov (1963). However, the larvae are not immediately mobile.

\section{FUTURE RESEARCH}

\section{Mating}

There is a voluminous literature on mating behaviour, including its duration. Much less is known, however, about when mating occurs and the conditions that induce mating (ecological, behavioural, physiological or anatomical). It is reported that Tityus bahiensis mates throughout the year (Matthiesen, 1968). Comparatively little (except Peretti's studies) is known about the number of times a male is capable of mating (i.e. producing a spermatophore) during a given season. As for females it is still unknown what a female's pre-requisites for mating are and whether it mates more than once during a breeding season.

\section{Gestation}

Reviewing this subject I was struck by the lack of information on the gestation period. Gestation starts with the fertilization of ova (this does not necessarily occur at the same time as the insemination of the female) and ends with parturition. Accurate data on the time fertilization are difficult to obtain. However, once the time interval between insemination and fertilization is known it will be easy to quantify the period and duration of gestation. There is no data on the frequency of gestations (annual 
and otherwise) and the time between two subsequent gestations.

\section{Parturition}

The lack of data on the number of parturitions per female makes it impossible to determine the reproductive potential of a female scorpion. Is a female capable of giving birth more than once in her lifetime (iteroparous)? If so, can females breed each year? These questions are of importance for evaluating population ecology, recruitment rates and survival.

\section{Birth}

It is important to obtain more data on the time it takes a larva of an apoikogenic scorpion to rid itself of its birth membrane. The times cited in the literature range from "soon after" to $2 \mathrm{~h}$. This information is important for addressing the following two questions:

1. Is a scorpion whose larvae "hatch" from eggs two hours after they are "laid" viviparous or ovoviviparous?

2. Is the likelihood of these larvae being killed by predators similar or greater than that of viviparous larvae?

\section{CONCLUSIONS}

In spite of centuries of observations on scorpions in the field and experiments in the laboratory the level of understanding of important aspects of the reproductive ecology of scorpions is still rudimentary. More accurate observations and careful planning of experiments are needed for a better understanding of scorpion reproduction.

ACKNOWLEDGEMENT. I am greatly indebted to the following colleagues for sharing with me some of their thoughts on the subjects discussed: L. de Armas, H. Greven, W. Lourenço, T. Makioka, A. Peretti, L. Ross, D. Sissom and R. Stockmann. Several students (alas, too many to be mentioned by name) assisted during this long-term study by helping to maintain many live scorpions, each of which was kept individually, and the mealworm culture over a period of 27 years. Skillful technical assistance in microscopy (LM, SEM) was provided by $\mathrm{M}$. Rosenberg my collaborator in this research for more than 10 years. To all of them I am most grateful.

\section{REFERENCES}

AвUSHama F.T. 1968: Observations on the mating behaviour and birth of Leiurus quinquestriatus (H. \& E.), a common scorpion species in the central Sudan. Rev. Zool. Bot. Afr. 77: $37-43$.

ANGERMANN H. 1957: Über Verhalten, Spermatophorenbildung und Sinnesphysiologie von Euscorpius italicus Hbst. und verwandten Arten (Scorpiones, Chactidae). Z. Tierpsychol. 14: 276-302.

Armas L.F. DE 1980: Aspectos de la biología de algunos escorpiones cubanos. Poeyana 211: 1-23.

ARMAS L.F. DE 1987: Copula multiple en escorpiones (Arachnida: Scorpiones). Misc. Zool. No. 30: 1-2.

Armas L.F. de \& Hernández Contreras N. 1981: Gestación y desarrollo postembrionario en algunos Centruroides (Scorpionida: Buthidae) de Cuba. Poeyana 217: 1-10.

Benton T. 2001: Reproductive ecology. Chapter 11. In Brownell P. \& Polis G. (eds): Scorpion Biology and Research. Oxford University Press, New York, pp. 278-301.
Brown C.A. 2001: Allometry of offspring size and number in scorpions. In Fet V. \& Selden P.A. (eds): Scorpions. British Arachnological Society, Burnham Beeches, pp. 307-315.

Dehghani R., Khamechian T. \& Miranzadeh M.B. 2007: Surveying on the biologic behaviors of Hemiscorpius leptutus Peters 1861, scorpion in laboratory (Khuzestan, Iran) (Scorpions: Hemiscorpiidae). Pak. J. Biol. Sci. 10: 3097-3102.

FARLEY R.D. 1996: Formation of maternal trophic structures for embryos of Paruroctonus mesaensis (Scorpionida: Vaejovidae). Rev. Suisse Zool. (H.S.) 1: 189-202.

FARLeY R.D. 1999: Scorpiones. In Harrison F.W. \& Foelix R.F. (eds): Microscopical Anatomy of Invertebrates. Vol. 8 A. Chelicerata Arthropoda. Wiley, New York, pp. 117-222.

FRANCKE O.F. 1979: Observations on the reproductive biology and life history of Megacormus gertschi Diaz (Scorpiones: Chactidae: Megacorminae). J. Arachnol. 7: 223-230.

FRANCKE O.F. 1981: Birth behavior and life history of Diplocentrus spitzeri Stahnke (Scorpiones: Diplocentridae). Southwest. Nat. 25: 517-523.

FRANCKE O.F. 1982: Parturition in scorpions (Arachnida, Scorpiones): a review of the ideas. Rev. Arachnol. 4: 27-37.

HJELLE J.T. 1974: Observation on the birth and post-birth behavior of Syntropis macrura Kraepelin (Scorpionida: Vaejovidae). J. Arachnol. 1: 221-227.

Kovoor J., Lourenço W.R. \& Muñoz-Cuevas A. 1987: Conservation spermatozoides dans les voies génitale des femelles et biologie de la reproduction des Scorpions (Chélicérates). $C$. R. Acad. Sci. Paris (Ser. III) 304: 259-264.

MAHSBERG D. 2001: Brood care and social behavior. In Brownell P. \& Polis G. (eds): Scorpion Biology and Research. Oxford University Press, New York, pp. 259-277.

MAKIOKA T. 1992: Reproductive biology of the viviparous scorpion, Liocheles australasiae (Fabricius) (Arachnida, Scorpiones, Ischnuridae). II. Repeated pregnancies in virgins. Int. $J$. Invert. Reprod. Dev. 21: 161-166.

MAKIOKA T. \& KoIKE K. 1985: Reproductive biology of the viviparous scorpion, Liocheles australasiae (Fabricius) (Arachnida, Scorpiones, Scorpionidae). I. Absence of males in two natural populations. Int. J. Invert. Reprod. Dev. 8: 317-323.

Mathew A.P. 1960: Embryonic nutrition in Lychas tricarinatus. J. Zool. Soc. India 12: 220-228.

Mathew A.P. 1962: Reproductive biology of Lychas tricarinatus (Simon). Biol. Bull. 123: 344-350.

Matthiesen F.A 1968: On the sexual behaviour of some Brazilian scorpions. Rev. Brasil Pesq. Méd. Biol. 1: 93-96.

MatThiesen F.A. 1970: Le développement post-embryonnaire du scorpion Buthidae: Tityus bahiensis (Perty, 1834). Bull. Mus. Nat. Hist. Nat. (2nd Ser.) 41: 1367-1370.

Outeda-Jorge S., Mello T. \& Pinto-da-Rocha R. 2009: Litter size, effects of maternal body size, and date of birth in South American scorpions (Arachnida: Scorpiones). Zoologia 26: $43-53$.

Peretti A.V. 1997: Alternativas de gestación y producción de crias en seis escorpiones argentinos (Scorpiones: Buthidae, Bothriuridae). Iheringia (Sér. Zool.) 82: 25-32.

Peretti A.V. 2010: An ancient indirect sex model: single and mixed patterns in the evolution of scorpion genitalia. Chapter 12. In Leonard J.L. \& Cordoba-Aguilar A. (eds): The Evolution of Primary Sexual Characters in Animals. Oxford University Press, Oxford, pp. 218-248.

Polis G.A. \& FARLEY R.D. 1979: Characteristics and environmenmtal determinants of natality, growth and maturity in a natural population of the desert scorpion, Paruroctonus mesaensis (Scorpionida: Vaejovidae). J. Zool. 187: 517-542. 
Polis G.A. \& Mohnac M. 1990: Mating by female scorpions while still carrying young. J. Arachnol. 18: 364-365.

Polis G.A. \& Sissom W.D. 1990: Life history. In Polis G.A (ed.): The Biology of Scorpions. Stanford University Press, Stanford, pp. 161-218.

Probst P. 1968: Mehrmalige Trachtigkeit und Dauernder Tagzeit beim Skorpion Isometrus maculatus De Geer (Fam. Buthidae). Rev. Suisse Zool. 75: 1066-1070.

Probst P.J. 1972: Zur Fortpflanzunsbiologie und zur Entwicklung der Giftdrusen beim Skorpion Isometrus maculatus (De Geer, 1778) (Scorpiones: Buthidae). Acta Trop. 29: 1-87.

Rosin R. \& Shulov A. 1963: Studies in the scorpion Nebo hierochonticus. Proc. Zool. Soc. Lond. 140: 547-575.

Ross L.K. 2007: Development and care of early-instar Pandinus imperator (Scorpiones: Scorpionidae). Forum Mag. Am. Tarantula Soc. 16: 24-28.

Ross L.K. 2009: Notes on gestation periods and litter size in the arenicolous buthid scorpion Leiurus quinquestriatus (Ehrenberg, 1828) (Scorpiones: Buthidae). J. Venom. Anim. Toxins Trop. Dis. 15: 347-352.

Shorthouse D.J. 1971: Studies on the Biology and Energetics of the Scorpion Urodacus yaschenkoi. Ph.D. thesis, Australian National University, Canberra, $163 \mathrm{pp}$.

Shorthouse D.J. \& Marples T.G. 1982: The life stages and population dynamics of an arid zone scorpion Urodacus yaschenkoi (Birula 1903) Austr. J. Ecol. 7: 109-118.

Shulov A. \& Amitai P. 1960: Observations sur les scorpions Orthochirus innesi E. Sim. 1910, ssp, negebensis nov. Arch. Inst. Pasteur Afr. Noir 38: 117-129.

Shulov A., Rosin A. \& Amitai P. 1960: Parturition in scorpions. Bull. Res. Council Isr. (B) 9: 65-69.

Subburam V. \& Gopalakrishna Reddy T. 1978: Breeding season and gestation period of the scorpion Heterometrus fulvipes. J. Bombay Nat. Hist. Soc. 75: 513-514.
Subburam V. \& Gopalakrishna Reddy T. 1981: Morphology of the embryonic stages of the viviparous scorpion, Heterometrus fulvipes: A photographic study. J. Morphol. 169: 275-281.

Tourtlotte G.I. 1974: Studies on the biology and ecology of the northern scorpion, Paruroctonus boreus (Girard). Great Basin Nat. 34: 167-179.

VARELA J.C. 1961: Gestación, nacimiento y eclosión de Bothriurus bonariensis var bonariensis (Koch, 1842) (Bothriuridae, Scorpiones). Rev. Fac. Human. Cie. Montevideo 19: 225-244.

WARBURG M.R. 2001: Scorpion reproductive strategies, potential and longevity: an eco-morphologist's interpretation. In Fet V. \& Selden P.A. (eds): Scorpions. British Arachnological Society, Burnham Beeches, pp. 349-358.

WARBURG M.R. 2010: The scorpion female's reproductive system; a partial review. Anat. Rec. 293: 1738-1754.

WARBURG M.R. 2011: Scorpion reproductive strategies, allocation and potential; a partial review. Eur. J. Entomol. 108: 173-181.

WARBURG M.R. 2012: Ovulation, fertilization and embryonic development in scorpions: a partial review. Afr. Entomol. [in press].

WiLliams S.C. 1969: Birth activities of some North American scorpions. Proc. Calif. Acad. Sci. (4th ser.) 37: 1-24.

Williams S.C. 1987: Scorpion bionomics. Annu. Rev. Entomol. 32: 275-295.

YAMAZAKI K. \& MAKIOKA T. 2001: Ovarian structural features reflecting repeated pregnancies and parturitions in a viviparous scorpion, Liocheles australasiae. Zool. Sci. 1: 277-282.

YAMAZAKI K. \& MAKIOKA T. 2005: Parthenogenesis through five generations in the scorpion Liocheles australasiae (Fabricius 1775) (Scorpiones, Ischnuridae). J. Arachnol. 33: 852-856.

Received August 19, 2011; revised and accepted November 18, 2011 